\title{
Protective effect of dexmedetomidine on perioperative myocardial injury in patients with Stanford type-A aortic dissection
}

\author{
(D) Dalong Wang ${ }^{*}$ \\ (iD) Quan Lin' \\ (iD) Meiqing Du ${ }^{1}$ \\ (iD) Guanrong Zheng ${ }^{1}$ \\ (iD) Weimin $X u^{1}$ \\ (D) Haishan Zhang ${ }^{1}$ \\ (iD) Ke Liu'
}

\begin{abstract}
1. Department of Anesthesiology, Shengli Oilfield Central Hospital, Dongying 257000, China. 2. Department of Administration, Shengli Oilfield Central Hospital, Dongying 257000, China.

\section{SUMMARY}

OBJECTIVE: To investigate the protective effect and mechanism of dexmedetomidine (Dex) on perioperative myocardial injury in patients with Stanford type-A aortic dissection (AD).

METHODS: Eighty-six patients with Stanford type-A AD were randomly divided into Dex and control groups, with 43 cases in each group. During the surgery, the control group received the routine anesthesia, and the Dex group received Dex treatment based on routine anesthesia. The heart rate (HR) and mean arterial pressure (MAP) were recorded before Dex loading (tO), 10 min after Dex loading ( $t 1)$, at the skin incision ( $t 2)$, sternum sawing ( $t 3)$, before cardiopulmonary bypass ( $t 4)$, at the extubation ( $t 5)$, and at end of surgery ( $t 6)$. The blood indexes were determined before anesthesia induction (TO) and postoperatively after 12h (T1), 24h (T2), 48h (T3), and 72h (T4).

RESULTS: At 12 and 13 , the HR and MAP in the Dex group were lower than in the control group $(P<0.05)$. Compared with the control group, in the Dex group at T1, T2, and T3, the serum creatine kinase-MB, cardiac troponin-I, C-reactive protein, and tumor necrosis factor- $\alpha$ levels were decreased, and the interleukin-10 level, the serum total superoxide dismutase, and total anti-oxidant capability increased, while the myeloperoxidase and malondialdehyde levels decreased (all $P<0.05$ ).

CONCLUSIONS: Dex treatment may alleviate perioperative myocardial injury in patients with Stanford type-A AD by resisting inflammatory response and oxidative stress.

KEYWORDS: Dexmedetomidine. Aneurysm, dissecting. Myocardium. Oxidative stress. Inflammation/metabolism. Inflammation mediators/ metabolism.

\section{INTRODUCTION}

Aortic dissection (AD) refers to the tearing of the aortic intima under the action of certain pathogenic factors. In this disease, the blood flows into the middle layer of the aortic wall through the torn intimal orifice, which causes the intima to exfoliate along the aortic cavity to form a hematoma, i.e., pseudolumen. 
$\mathrm{AD}$ is a rare but fatal disease that is dangerous and progresses rapidly. Patients with AD often die from hematoma rupture, massive hemorrhage, and pericardial tamponade' ${ }^{1}$. The high-risk factors of AD include hypertension, Marfan's syndrome, aortic degeneration, cocaine abuse, atherosclerosis, and so on, and hypertension and Marfan's syndrome are the most common $^{2,3}$. According to the location of the primary rupture and the treatment methods, $\mathrm{AD}$ is classified as Standford type A and B. Standford type-A AD is more common, which involves the ascending aorta. In Standford type-A AD, the period from the onset to the $14^{\text {th }}$ day is the acute phase, during which the active drug treatment to control blood pressure and appropriate analgesia and sedation should be performed ${ }^{4}$. At present, surgery is the most effective method to treat Stanford type-A AD, but the operation process is complicated, with great trauma and bleeding, and the incidences of postoperative complications and mortality rate are high ${ }^{5}$. The acute myocardial infarction, pericardial tamponade, hypotension, shock, and old age are the main risk factors for early death after surgery in AD patients ${ }^{6}$. Therefore, strengthening the perioperative myocardial protection and blood pressure management are of great significance to improve the success rate of surgery and prognosis of patients. Dexmedetomidine (Dex) is an imidazole derivative that selectively activates the $\alpha 2$ adrenergic receptors. It is widely used in clinical anesthesia assistance due to its sedative, analgesic, and sympathetic blockade effects ${ }^{7}$. Dex can reduce the number of other drugs to achieve the best intoxication effect while minimizing side effects. At present, there are many animal experiments on the protective effect of Dex on myocardium ${ }^{8,9}$. Clinical studies mainly focus on cardio-protection of Dex during coronary artery bypass grafting ${ }^{10,11}$, but the application of Dex for Standford type-A AD is rarely reported. The aim of this study was to investigate the protective effect and mechanism of Dex on perioperative myocardial injury in patients with Stanford type-A AD, so as to provide a reference for its further clinical application.

\section{SUBJECTS AND METHODS}

\section{Subjects}

The clinical data of 86 patients with Stanford type-A AD receiving surgery in the Shengli Oilfield Central Hospital (Dongying, China) from July 2014 to December 2017 were selected. There were 56 males and 30 females, aged 28-69 years, with an average age of $47.52 \pm 8.31$ years. The body mass index (BMI) was $23.11 \pm 4.92 \mathrm{~kg} / \mathrm{m}^{2}$. There were 19 cases of smoking history, 50 cases of hypertension history, and 11 cases of diabetes mellitus history. The American Society of Anesthesiologists (ASA) grade was III (49 cases) or IV (37 cases). The anesthesia duration was $254.48 \pm 55.04$ min. The cardiopulmonary bypass (CPB) duration was $138.98 \pm 28.12 \mathrm{~min}$. The surgery duration was $275.28 \pm 59.28 \mathrm{~min}$. Eighty-six patients were randomly divided into Dex and control groups, 43 cases in each group. There was no significant difference in gender, age, BMI, smoking history, hypertension history, diabetes mellitus history, ASA grade, anesthesia duration, CPB duration, or surgery duration between Dex and control groups $(\mathrm{P}>0.05)$. This study was in line with the medical ethics standards and was approved by the ethics committee of the Shengli Oilfield Central Hospital. Informed consent was obtained from all subjects.

\section{Inclusion and exclusion criteria}

The inclusion criteria were as follows: $18-70$ years old; Stanford type-A AD confirmed by clinical and imaging examinations, within 14 days of onset; normal liver and kidney function. The exclusion criteria were as follows: complicated with other cardiopulmonary diseases; neurological dysfunction; obvious severe tissue perfusion defects; a long-term history of sedative use.

\section{Anesthesia and intraoperative monitoring}

In the two groups, after admission, oxygen was inhaled by mask, and ECG and pulse oxygen saturation were monitored routinely. At the same time, a bispectral index monitor was used to monitor the depth of anesthesia. The peripheral venous access of one upper limb was opened and a compound sodium lactate Ringer solution was intravenously dripped. Left-radial-artery puncture catheterization was performed to monitor the arterial blood pressure. The induction and maintenance of anesthesia were the same in the two groups. An intravenous injection of midazolam (0.05-0.1 mg/kg), etomidate (0.10-0.30 mg/ $\mathrm{kg})$, rocuronium $(1.00 \mathrm{mg} / \mathrm{kg})$ and sufentanil $(1.00-2.00$ $\mu \mathrm{g} / \mathrm{kg}$ ) was used for the induction of anesthesia. After endotracheal intubation, mechanical ventilation was performed. The oxygen concentration was $60 \%$, with an oxygen flow rate of 0.5-1.0 L/min, a tidal volume of $8-10 \mathrm{ml} / \mathrm{kg}, \mathrm{I} / \mathrm{E}$ ratio of $1: 2$, and a respiratory rate of 10-14 times/min. The end-expiratory partial pressure 
of carbon dioxide was maintained at $35-45 \mathrm{mmHg}$. The right internal jugular vein was punctured, and a three-chamber 7F central venous catheter (depth 13-15 $\mathrm{cm}$ ) was placed for infusion and monitoring of the central venous pressure. Intravenous infusion of sufentanil [0.5-1.5 $\mu \mathrm{g} /(\mathrm{kg} \cdot \mathrm{h})]$ and propofol [4-6 $\mathrm{mg} /(\mathrm{kg} \cdot \mathrm{h})]$ was used for anesthesia maintenance. Intermittent intravenous injection of pancuronium was performed to maintain muscle relaxation. The intraoperative bispectral index was maintained at 40-60. In the Dex group, after anesthesia induction, Dex was intravenously dripped ( $1 \mathrm{ug} / \mathrm{kg}$ ) for $10 \mathrm{~min}$, followed by intravenously dripping at a rate of $5 \mu \mathrm{g} /(\mathrm{kg} \cdot \mathrm{h})$ to the end of surgery. The control group received an intravenous drip of $0.9 \%$ sodium chloride after anesthesia, using the same volume and methods as in the Dex group. All surgical operations were performed under general anesthesia, deep hypothermic circulatory arrest, and selective cerebral perfusion, and were completed by the same group of surgeons.

\section{Hemodynamic monitoring}

The heart rate (HR) and mean arterial pressure (MAP) were recorded before Dex loading (to), $10 \mathrm{~min}$ after Dex loading (t1), at the skin incision (t2), sternum sawing ( $\mathrm{t} 3$ ), before cardiopulmonary bypass ( $\mathrm{t} 4)$, at the extubation ( $t 5)$, and at the end of surgery ( $t 6)$.

\section{Determination of blood indexes}

The peripheral venous blood samples were collected before anesthesia induction (TO), and postoperatively after $12 \mathrm{~h}$ (T1), $24 \mathrm{~h}$ (T2), $48 \mathrm{~h}$ (T3), and $72 \mathrm{~h}$ (T4). After centrifuging at $3000 \mathrm{rpm}$ for $10 \mathrm{~min}$, the serum was stored in a refrigerator at $-70{ }^{\circ} \mathrm{C}$. The serum levels of myocardial injury indexes, including creatine kinase-MB (CK-MB) and cardiac troponin-I (cTnI), inflammatory cytokines, including C-reactive protein (CRP), tumor necrosis factor- $\alpha$ (TNF- $\alpha$ ), interleukin (IL)-6, and IL-10 and oxidative stress indexes, including total superoxide dismutase (TSOD), total anti-oxidant capability (TAOC), myeloperoxidase (MPO) and malondialdehyde (MDA), were determined by enzymelinked immunosorbent assay. The operations were carried out strictly according to the instructions of the kits (R\&D Systems, Minneapolis, MN, USA).

\section{Statistical analysis}

Statistical analyses were performed using SPSS 20.0 (SPSS, Chicago, IL, USA). The enumeration data were presented as number and rate, and the comparison between the two groups was performed using the $\chi^{2}$ test. The measurement data were presented as mean \pm standard deviation, and the comparison between the two groups was performed using the t-test. Statistical significance was accepted at twosided $\mathrm{P}<0.05$.

\section{RESULTS}

Comparison of HR and MAP between two groups

As shown in Figure 1, from to to t6, the HR and MAP in the control and Dex groups gradually increased, followed by a decrease. At $\mathrm{t} 2$ and $\mathrm{t} 3$, the HR and MAP in the Dex group were significantly lower than those in the control group $(\mathrm{P}<0.05)$. At all the other time points, there was no significant difference in the indexes between the two groups $(\mathrm{P}>0.05)$.

FIGURE 1. COMPARISON OF HR AND MAP BETWEEN THE DEX AND CONTROL GROUPS.

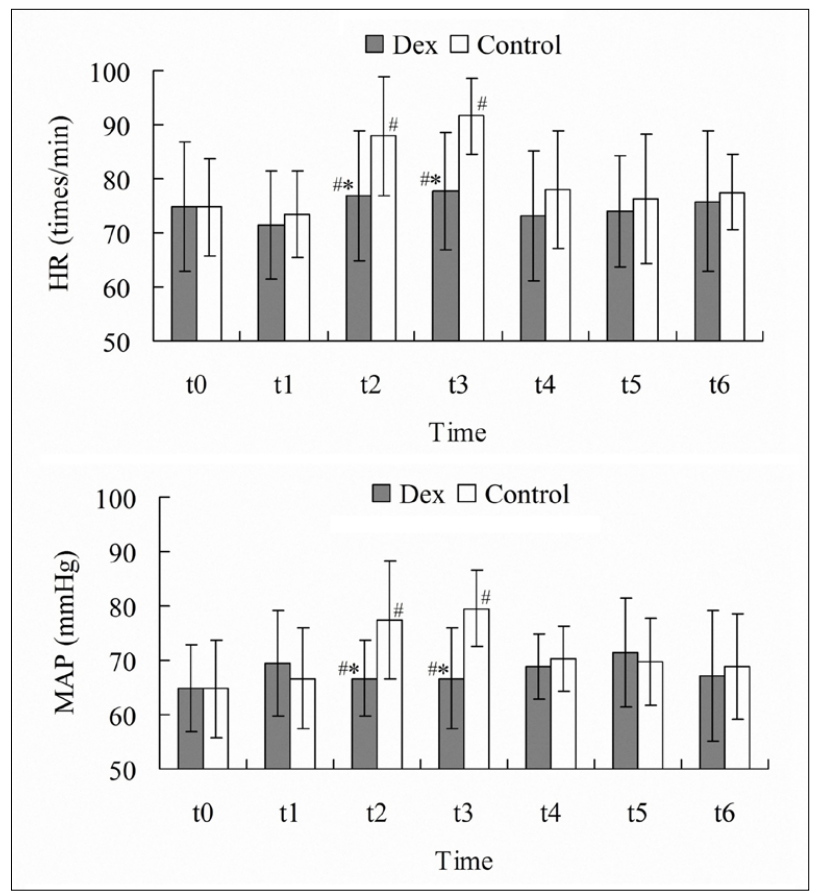

$\# \mathrm{P}<0.05$ compared with t0; ${ }^{*} \mathrm{P}<0.05$ compared with the control group. $\mathrm{HR}$, heart rate; MAP, mean arterial pressure; Dex, dexmedetomidine.

Comparison of serum CK-MB and cTnl levels between two groups

At TO, T1, T2, T3, and T4, the serum CK-MB level in the Dex group was $2.92 \pm 0.41,24.5 \pm 3.43,16.83 \pm 2.36$, $15.04 \pm 2.10$, and $7.21 \pm 0.98 \mathrm{ng} / \mathrm{ml}$, respectively; in the control group, it was $2.82 \pm 0.39,29.7 \pm 4.16,27.7 \pm 3.88$, $17.21 \pm 2.38$, and $8.03 \pm 1.12 \mathrm{ng} / \mathrm{ml}$, respectively. At TO, 
T1, T2, T3, and T4, the cTnI level in the Dex group was $0.33 \pm 0.052 .21 \pm 0.31,1.63 \pm 0.22,1.42 \pm 0.20$, and $0.89 \pm 0.12 \mathrm{ng} / \mathrm{ml}$, respectively; in the control group, it was $0.31 \pm 0.04,3.27 \pm 0.45,2.35 \pm 0.32,2.52 \pm 0.35$, and $1.31 \pm 0.18 \mathrm{ng} / \mathrm{ml}$, respectively. From TO to T4, the serum CK-MB and cTnI levels in the Dex and control groups increased, followed by a decrease. Each of them was the highest at T1. In addition, at T1, T2, and T3, the serum CK-MB level in the Dex group was significantly lower than that in the control group ( $\mathrm{P}$ $<0.05)$. At T1, T2, T3, and T4, the serum cTnI level in the Dex group was significantly lower than that in the control group, respectively $(\mathrm{P}<0.05)$.

Comparison of serum CRP, TNF- $\alpha$, IL-6, and IL-10 levels between the two groups

With the time prolonging from $\mathrm{TO}$ to $\mathrm{T} 4$, the serum CRP, TNF- $\alpha$, and IL- 6 levels in each group increased, followed by a decrease. Over time, the serum IL-10 level in each group decreased, followed by an increase. In each group, the serum CRP level at T2, TNF- $\alpha$ level at T2, and IL- 6 level at T1 were the highest among the 5 time points, and the IL-10 level at T1 was the lowest among the 5 time points. In addition, compared with the control group, in the Dex group, the CRP level at T1, T2, and T3 and TNF- $\alpha$ and IL- 6 levels at T1, T2, T3, and $\mathrm{T} 4$ were significantly decreased $(\mathrm{P}<0.05)$, while the IL-10 level at T1, T2, T3, and T4 was significantly increased $(\mathrm{P}<0.05)$ (Figure 2).

Comparison of serum TSOD, TAOC, MPO, and MDA levels between the two groups

Figure 3 shows that, from TO to T4, the serum TSOD and TAOC levels in each group decreased, followed by a gradual increase, and the serum MPO and MDA levels in each group increased, followed by a gradual decrease. In each group, the TSOD and TAOC levels at $\mathrm{T} 1$ were the highest among the 5 time points, and the MPO and MDA levels at T1 were the lowest among the 5 time points. In addition, compared with the control group, in the Dex group, the TSOD and TAOC levels at $\mathrm{T} 1, \mathrm{~T} 2$, and $\mathrm{T} 3$ were significantly increased $(\mathrm{P}<0.05)$, and the MPO level at T1, T2, and T3 and MDA level at T1, $\mathrm{T} 2$, T3, and T4 were significantly decreased $(\mathrm{P}<0.05)$.

\section{DISCUSSION}

In $\mathrm{AD}$, as the blood continuously flows into the middle layer through the torn intimal orifice, the aortic intima exfoliates to form a hematoma, which leads to the weakness of the aortic wall. The increase of blood pressure and tachycardia caused by any reason during the onset of AD may lead to an increase of shear force in the aortic wall and increase the risk of intimal rupture ${ }^{12,13}$. Therefore, active sedation and

FIGURE 2. COMPARISON OF SERUM CRP, TNF- $\alpha$, IL-6, AND IL-10 LEVELS BETWEEN THE DEX AND CONTROL GROUPS.

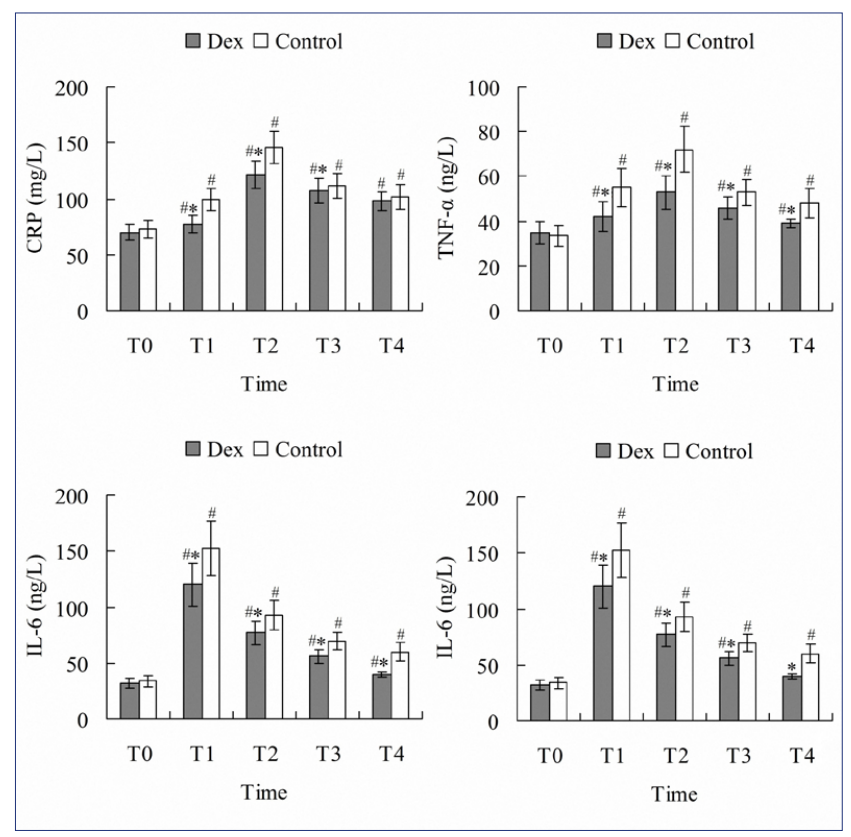

$\# \mathrm{P}<0.05$ compared with TO; ${ }^{*} \mathrm{P}<0.05$ compared with the control group. CRP, C-reactive protein; TNF- $\alpha$, tumor necrosis factor- $\alpha$; IL, interleukin; Dex, dexmedetomidine.

FIGURE 3. COMPARISON OF SERUM CRP, TNF- $\alpha$, IL-6, AND IL-10 LEVELS BETWEEN THE DEX AND CONTROL GROUPS.

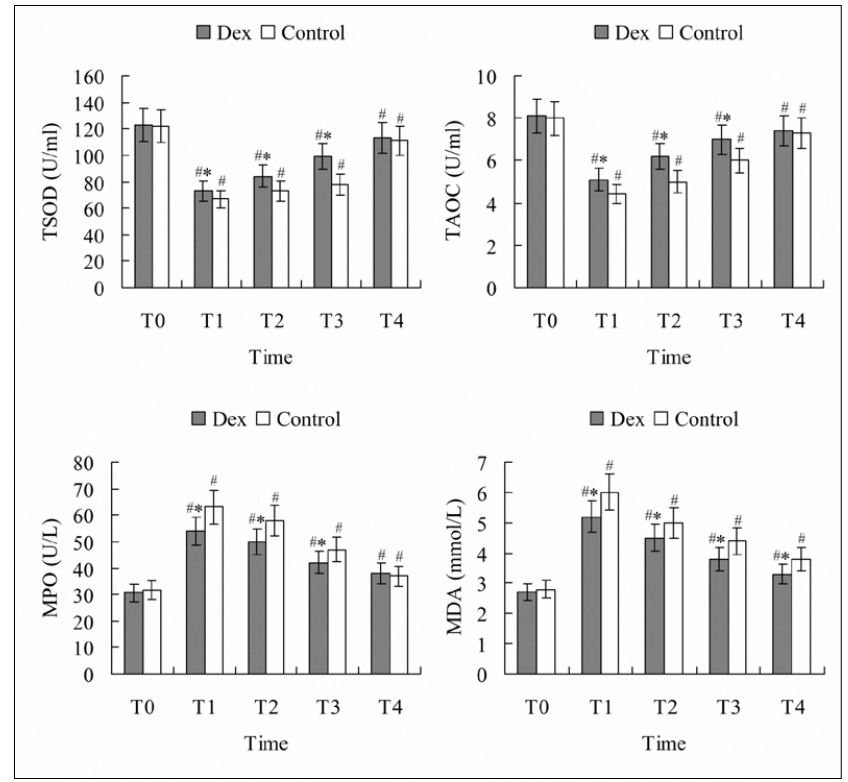

\#P $<0.05$ compared with TO; ${ }^{*}>0.05$ compared with the control group. TSOD, total superoxide dismutase; TAOC, total anti-oxidant capability; MPO, myeloperoxidase; MDA, malondialdehyde; Dex, dexmedetomidine. 
analgesia, strict control of blood pressure, maintenance of hemodynamics, and reduction of shear force in the aortic wall are the basic principles for the perioperative management of patients with acute AD. This study investigated the protective effect of Dex on patients with Stanford type-A AD. Results showed that, compared with the patients using routine anesthesia, in patients additionally using Dex, the HR and $\mathrm{MAP}$ at $\mathrm{t} 2$ and $\mathrm{t} 3$ were significantly decreased. This indicates that the Dex treatment can further maintain hemodynamic stability during surgery in patients with Stanford type-A AD.

CK-MB is a specific myocardial isozyme, which is abundant in myocardial cells. Under normal circumstances, the serum CK-MB level is very low. When the myocardial cells are damaged, CK-MB is released into the blood in large quantities. It has high sensitivity in judging the myocardial damage and is often used in the clinical diagnosis of myocarditis and for evaluating its severity ${ }^{14}$. The cardiac troponin ( $(\mathrm{Tn})$ molecule is spherical and consists of three subunits including cTnI, cTnT, and cTnC. cTnI in the myocardium is different from that in other muscle tissues. Meanwhile, the molecular weight of $\mathrm{cTnI}$ is small. In the early stage of myocardial injury, it can be rapidly released into the blood to increase its blood concentration. cTnI can be used as an early diagnostic index for myocardial injury ${ }^{15}$. Results of this study showed that, at T1, T2, and T3, the serum CK-MB level in the Dex group was significantly lower than that in the control group. At T1, T2, T3, and T4, the serum cTnI levels in the Dex group were significantly lower than those in the control group. This indicates that the Dex treatment can alleviate perioperative myocardial injury in patients with Stanford type-A AD.

The occurrence, development, and clinical manifestations of $\mathrm{AD}$ are significantly correlated with the inflammatory response ${ }^{16}$. CRP is a non-specific marker of inflammation. It is the most powerful predictor and risk factor of cardiovascular disease. Its level is increased rapidly in inflammation, injury, and infectious diseases. A previous study has shown that the serum level of CRP is increased significantly in patients with $\mathrm{AD}^{17}$. TNF- $\alpha$ is produced by mononuclear macrophages and plays a central role in the inflammatory response. It can promote the inflammatory response by injuring vascular endothelial cells, increasing the expression of endothelial cell-adhesion molecules and other inflammatory factors $^{18}$. IL-6 is also a key component of inflammatory response. It can induce hepatocytes to synthesize acute-phase proteins and regulate macrophages to increase the TNF- $\alpha$ level $^{19}$. IL-10 is an endogenous anti-inflammatory factor, which can inhibit the expression of inflammatory mediators such as TNF- $\alpha$ and IL- $6^{20}$. In the present study, compared with the control group, in the Dex group, the CRP level at T1, T2, and T3 and TNF- $\alpha$ and IL- 6 levels at T1, T2, $\mathrm{T} 3$, and $\mathrm{T} 4$ were significantly decreased, and the IL-10 levels at T1, T2, T3, and T4 were significantly increased. This suggests that the Dex treatment can reduce the inflammatory response in patients with Stanford type A AD, which may be related to its protective effect on myocardial injury.

During the formation of AD, the blockage of aortic branch vessels affects the blood flow, leads to ischemia and poor perfusion of corresponding tissues. The recanalization of vessels can lead to ischemia-reperfusion injury, which can cause a large number of neutrophils to accumulate in the lung, heart, and other organs. They activate degranulation and produce and release a large amount of oxygen free radicals, which cause oxidative stress damage ${ }^{21}$. Lipids in cells have a high affinity with oxygen free radicals. Oxygen free radicals attack lipids, which can damage cell structure and function and produce $\mathrm{MDA}^{22}$. MPO is the key enzyme catalyzing the generation of oxygen free radicals, and its content can also reflect the production of oxygen free radicals ${ }^{23}$. SOD and other antioxidant catalytic enzymes can scavenge oxygen free radicals to a certain extent. However, when oxygen free radicals are generated in large quantities and exceed the body's antioxidant capacity, SOD will be continuously consumed and TAOC will be reduced ${ }^{24}$. Results of this study showed that, compared with the control group, in the Dex group, the TSOD and TAOC levels at T1, T2, and T3 were significantly increased, and the MPO levels at $\mathrm{T} 1, \mathrm{~T} 2$, and $\mathrm{T} 3$ and MDA levels at $\mathrm{T} 1, \mathrm{~T} 2, \mathrm{~T} 3$, and T4 were significantly decreased. This indicates that the Dex treatment can reduce oxidative stress, thus alleviating myocardial injury in patients with Stanford type-A AD.

\section{CONCLUSION}

The Dex treatment can alleviate perioperative myocardial injury in patients with Stanford type-A AD. Its mechanism may be related to resistance to inflammatory response and oxidative stress. This study has 
provided a reference for further clinical application of Dex in AD surgery. However, the results of this study are obtained only from clinical manifestations and laboratory detections, and no myocardial pathological result has been found. In addition, the correlations among different indexes are not analyzed. These are the limitations of this study, which need to be solved in further studies.

\section{Author's Contribution}

Ke Liu and Quan Lin designed the study. Dalong Wang and Meiqing Du participated in data collection. Guanrong Zheng and Weimin Xu performed the statistical analyses. Dalong Wang drafted the manuscript. Ke Liu and Haishan Zhang critically revised the manuscript. All authors read and approved the final manuscript.

\section{RESUMO}

OBJETIVO: Investigar o efeito protetor e o mecanismo da dexmedetomidina (Dex) na lesão perioperativa do miocárdio em doentes com dissecação aórtica Tipo A de Stanford (AD).

MÉTODos: Oitenta e seis pacientes com o Tipo A de Stanford foram aleatoriamente divididos em Dex e grupos de controle, 43 casos em cada grupo. Durante a cirurgia, o grupo de controle recebeu a anestesia de rotina, e o grupo Dex recebeu tratamento Dex baseado na anestesia de rotina. A frequência cardíaca (AR) e a pressão arterial média (MAP) foram registradas no momento anterior ao Dex carregar ( $t 0), 10$ minutos após o Dex carregar ( $t 1)$, incisão cutânea (t2), serragem de esterno ( $t 3)$, antes do bypass cardiopulmonar ( $t 4$ ), extubação (t5) e fim da cirurgia ( $t 6)$. Os índices de sangue foram determinados no momento antes da indução da anestesia (TO) e no pós-operatório 12 horas (T1), 24 horas (T2), 48 horas (T3) e 72 horas (T4).

RESULTADOS: Em T2 e t3, o RH e o MAP do grupo Dex foram inferiores ao grupo de controle (p<0,05). Em comparação com o grupo de controle, no grupo Dex em T1, T2 e T3, os níveis séricos de creatina quinase-MB, troponina-I, proteína C-reativa e necrose do fator- $\alpha$ do tumor diminuíram, o nível interleucina-10 aumentou, o desalinhamento total do superóxido sérico e a capacidade antioxidante total aumentaram e os níveis de mielopeperóxido e malondialdeído diminuíram (todos $p<0,05$ ).

CONCLUSÃo: O tratamento com Dex pode aliviar a lesão do miocárdio perioperativo em doentes com o Tipo A de Stanford por resistência à resposta inflamatória e ao estresse oxidativo.

PALAVRAS-CHAVE: Dexmedetomidina. Aneurisma dissecante. Miocárdio. Estresse oxidativo. Inflamação/metabolismo. Mediadores da inflamação/metabolismo.

\section{REFERENCES}

1. Karthikesalingam A, Holt PJ, Hinchliffe RJ, Thompson MM, Loftus IM. The diagnosis and management of aortic dissection. Vasc Endovascular Surg. 2010;44(3):165-9.

2. Chow SL. Acute aortic dissection in a patient with Marfan's syndrome complicated by gestational hypertension. Med J Aust. 1993;159(11-12):760-2.

3. Larson EW, Edwards WD. Risk factors for aortic dissection: a necropsy study of 161 cases. Am J Cardiol. 1984;53(6):849-55.

4. Hagan PG, Nienaber CA, Isselbacher EM, Bruckman D, Karavite DJ, Russman PL, et al. The International Registry of Acute Aortic Dissection (IRAD): new insights into an old disease. JAMA. 2000;283(7):897-903.

5. Stöger G, Ríos M, Battellini R, Bracco D, Kotowicz V. Complex reoperation for late complications after acute type A aortic dissection surgery. Aorta (Stamford). 2015;3(6):195-8.

6. Zhang J, Jiang Y, Gao C, Feng J, Wang A. Risk factors for hospital death in patients with acute aortic dissection. Heart Lung Circ. 2015;24(4):348-53.

7. Gertler R, Brown HC, Mitchell DH, Silvius EN. Dexmedetomidine: a novel sedative-analgesic agent. Proc (Bayl Univ Med Cent). 2001;14(1):13-21.

8. Sun Y, Jiang C, Jiang J, Qiu L. Dexmedetomidine protects mice against myocardium ischaemic/reperfusion injury by activating an AMPK/PI3K/Akt/ eNOS pathway. Clin Exp Pharmacol Physiol. 2017;44(9):946-53.

9. Zhang JJ, Peng K, Zhang J, Meng XW, Ji FH. Dexmedetomidine preconditioning may attenuate myocardial ischemia/reperfusion injury by down-regulating the HMGB1-TLR4-MyD88-NF-kB signaling pathway. PLoS One. 2017;12(2):e0172006.
10. Ren J, Zhang H, Huang L, Liu Y, Liu F, Dong Z. Protective effect of dexmedetomidine in coronary artery bypass grafting surgery. Exp Ther Med. 2013;6(2):497-502.

11. Sulemanji DS, Dönmez A, Aldemir D, Sezgin A, Türkoglu S. Dexmedetomidine during coronary artery bypass grafting surgery: is it neuroprotective? A preliminary study. Acta Anaesthesiol Scand. 2007;51(8):1093-8.

12. Bossone E, Gorla R, LaBounty TM, Suzuki T, Gilon D, Strauss C, et al. Presenting systolic blood pressure and outcomes in patients with acute aortic dissection. J Am Coll Cardiol. 2018;71(13):1432-40.

13. Kuroki K, Sato A, Yamagami F, Nogami A, Aonuma K. Life-threatening aortic dissection with cardiac tamponade during catheter ablation for ventricular tachycardia originating from left coronary cusp. / Cardiovasc Electrophysiol. 2017;28(10):1224-5.

14. Winter R|, Koster RW, van Straalen |P, Gorgels |P, Hoek F|, Sanders GT. Critical difference between serial measurements of CK-MB mass to detect myocardial damage. Clin Chem. 1997;43(2):338-43.

15. Ilva T, Lund J, Porela P, Mustonen H, Voipio-Pulkki LM, Eriksson S, et al. Early markers of myocardial injury: $\mathrm{cTn}$ is enough. Clin Chim Acta. 2009;400(1-2):82-5.

16. Luo F, Zhou XL, Li JJ, Hui RT. Inflammatory response is associated with aortic dissection. Ageing Res Rev. 2009;8(1):31-5.

17. Makita S, Ohira A, Tachieda R, Itoh S, Moriai Y, Yoshioka K, et al. Behavior of $C$-reactive protein levels in medically treated aortic dissection and intramural hematoma. Am J Cardiol. 2000;86(2):242-4. 
18. Salas A, Sans M, Soriano A, Reverter JC, Anderson DC, Piqué JM, et al. Heparin attenuates TNF-alpha induced inflammatory response through a CD11b dependent mechanism. Gut. 2000;47(1):88-96.

19. Lin H, Zhang W, Zhou T, Li W, Chen Z, ji C, et al. Mechanism of microRNA-21 regulating IL-6 inflammatory response and cell autophagy in intervertebral disc degeneration. Exp Ther Med. 2017;14(2):1441-4

20. Vivier E, Ugolini S. Regulatory natural killer cells: new players in the IL-10 anti-inflammatory response. Cell Host Microbe. 2009;6(6):493-5.

21. Liao M, Liu Z, Bao J, Zhao Z, Hu J, Feng X, et al. A proteomic study of the aortic media in human thoracic aortic dissection: implication for oxidative stress. | Thorac Cardiovasc Surg. 2008;136(1):65-72, 72.e1-3.
22. Hultavist $M$, Hegbrant |, Nilsson-Thorell $C$, Lindholm T, Nilsson $P$, Lindén $\mathrm{T}$, et al. Plasma concentrations of vitamin C, vitamin $\mathrm{E}$ and/or malondialdehyde as markers of oxygen free radical production during hemodialysis. Clin Nephrol. 1997;47(1):37-46.

23. Sato N, Kashima K, Tanaka Y, Shimizu H, Mori M. Effect of granulocyte-colony stimulating factor on generation of oxygen-derived free radicals and myeloperoxidase activity in neutrophils from poorly controlled NIDDM patients. Diabetes. 1997;46(1):133-7.

24. Pigeolet E, Corbisier P, Houbion A, Lambert D, Michiels C, Raes M, et al. Glutathione peroxidase, superoxide dismutase, and catalase inactivation by peroxides and oxygen derived free radicals. Mech Ageing Dev. 1990;51(3):283-97. 